\title{
Tracking the local seismicity level in the active influence zone of the southern Uzbekistan reservoirs
}

\author{
Lutfulla Khamidov ${ }^{1 *}$, Mahmud Turapov $^{2}$, Soqijon Mahkamov ${ }^{3}$, Farkhod Artikov $^{1}$, and \\ Shavkat Suyunov ${ }^{2}$ \\ ${ }^{1}$ Institute of Seismology named after G.A. Mavlyanov of the Academy of Sciences of the Republic of \\ Uzbekistan, Tashkent, Uzbekistan \\ ${ }^{2}$ Tashkent Institute of Architecture and Civil Engineering, Tashkent, Uzbekistan \\ ${ }^{3}$ Specialized boarding school named after Abu Ali Ibn Sino, Tashkent, Uzbekistan
}

\begin{abstract}
Assessment of local seismicity caused by human engineering activity is a necessity after several earthquakes have been recorded in world practice, which destroyed a hydraulic structure, a dam and accompanied by human casualties.

The Tupalang, Gissarak and Pachkamar reservoirs, operated in southern Uzbekistan, are located in the mountain system of the southern part of the Tien Shan seismogenic fault.

According to the general seismic zoning, the zones where these reservoirs are located are classified as 8-9 magnitude shakes during strong earthquakes. Localisation of local earthquakes associated with the operation of these reservoirs is necessary for taking operational measures to prevent possible emergencies associated with an increase in the level of technogenic seismicity.

Methods for assessing the local seismic regime were used to track the level of local seismicity. The catalogs of local earthquakes occurring in the zone of active influence of reservoirs have been compiled.

The seismic activity levels and changes in the angle of inclination of the recurrence of earthquakes were determined for each object separately. The dependence of the variation in the level of local seismicity on the mode of operation of reservoirs has been revealed.

Several evidence of the negative impact of large hydraulic reservoirs on the deformation and seismic state of the zones of influence of reservoirs in southern Uzbekistan have been identified.
\end{abstract}

\section{Introduction}

In the complex of studies that contribute to ensuring the geodynamic safe operation of reservoirs in Uzbekistan, digital seismic monitoring is becoming a new direction [1]. It is based on the representative registration of seismic vibrations from small acts of brittle fracture in the side rock mass $[2,3]$.

\footnotetext{
* Corresponding author: hamidov_1@mail.ru
} 
By processing seismic records, the characteristics of destruction processes are assessed their position in space, released seismic energy, inelastic deformation in the source area [4]. The potential benefits of quantitative processing and interpretation of seismic events in the basin of reservoirs have been known for a long time [5, 6].

However, previous attempts to organise seismic monitoring in a planned mode in the reservoir zones of Uzbekistan were not successful, mainly due to technical limitations [7, 8, 9].

In the present, a number of new, interesting results have been obtained [1, 10, 11, 12]. Studies of seismic activity, changes in the maximum of energy classes in the areas of reservoirs of southern Uzbekistan, calculated from representative seismological data, have shown that the possibility of the existence of signs of technogenic influence on the geodynamics of the area and the background seismicity of the region is quite comparable.

Therefore, the isolation from the general seismicity of the background and its local technogenic part, the determination of the spatial grouped seismic events, which is characterised by the establishment of zones of interrelated local seismic events, possibly depending on the mode of operation of reservoirs, turned out to be quite in demand $[11,12$, $13,14]$.

The seismicity of the reservoir areas has been raised in several publications $[2,10,16$, $17,18]$. It has two main aspects $[1,2,6,19,20]$.

First, it is important to know the degree of natural tectonic activity in this area $[10,21]$.

It is necessary to determine the large earthquakes that have arisen here earlier, even before the start of the operation of reservoirs [17-19]. When analysing the catalog of earthquakes in Uzbekistan, the catalog of strong earthquakes in Eurasia, the map of the general seismic zoning of Uzbekistan, the answer to this question will be negative because special studies of local seismicity with instrumental means in the reservoir areas were carried out selectively [7-], [21].

However, it should be noted that several seismic stations $(\mathrm{s} / \mathrm{s})$ have been operating in the areas of intensive exploitation of reservoirs in Uzbekistan for more than 40 years $(\mathrm{s} / \mathrm{s}$ Charvak - and. Charvak, s / s Kampiravat - and. Andijan, s/s Shabad - vodka. Gissarak and others) $[8,9]$. But their materials were not involved in the compilation of local catalogs of earthquakes, including weak earthquakes.

Over the past decades, these stations have been working to control the stability of the dams of the respective reservoirs $[7,8,9,10]$. Their materials were practically not used in assessing local seismicity and the state of local geodynamics [10].

The first information that off-background earthquakes occur in the reservoirs of Uzbekistan was obtained in 1974 [7, 8]. A detailed analysis of records of seismic events by experts in assessing the stability of dams made it possible to say that several microseismic events in the Charvak and Andijan reservoirs are, in fact, micro tectonic natural earthquakes $[8,12]$.

The fact of registration of such events suggests that local earthquakes can occur in the zone of deformation effect of reservoirs $[1,10,12]$. They depend mainly on changes in the volume of reservoirs and the geological location of reservoirs.

The issue of local seismicity is important for a detailed specification of the seismic hazard of areas where reservoirs with high and mainly Earth dams are located in the mountainous area of southern Uzbekistan [8, 10, 22].

The second aspect of the problem of seismicity in the area of reservoirs is the possible induced seismicity in this area, which is a consequence of the intensive operation of the reservoir with a rather sharp change in their volumes in a short time [10, 16, 17, 22].

Several researchers believe that the operation of reservoirs will provoke an increase in seismic activity even at a great distance from it $[2,3,8,18,19]$. There is an opinion that 
rejects this possibility $[5,16,18,20]$. However, there is still no clear data to answer this question.

\section{Methods}

The analysis of known cases of excited earthquakes caused by the operation of reservoirs, described in $[1,10,11,12,22]$, made it possible to establish several empirical generalisations, taking into account the diversity of conditions of the geological structure of various reservoirs of southern Uzbekistan. Most epicenters are grouped into zones controlled by the structural features of a particular area:

Distribution of faults, fracture zones, the strike of structures, etc. [11, 22]. The existing regional network of seismic stations in the Republic of Uzbekistan allows receiving of data on earthquakes $K \geq 9$, where $K$ is the energy class.

To obtain the necessary information, in the areas where man-made objects are located, it is necessary to achieve registration of earthquakes of lower energy classes (at least from $\mathrm{K} \geq 7$ ).

On the other hand, it should be taken into account that the determination of the seismic activity variation A10 and the slope of the recurrence graph is based on the recurrence of earthquakes as a fundamental property of the seismic process.

Their use is associated, in particular, with the sometimes observed decrease in the slope of the recurrence graph before strong events [12, 23].

The recurrence slope is calculated from the continuous exponential distribution of earthquakes by class. In this case, the following generally known formulas are used [1, 9, 10]:

$\gamma$-frequency slope

$$
v=\log _{10} e \frac{1}{\sum_{i}^{N} K_{i} / N-K_{0}}
$$

root mean square error in a value

$$
S_{\gamma}=\frac{v}{\sqrt{N}}
$$

seismic activity A10

$$
A_{10}=\frac{1000 \cdot N \cdot\left(1-10^{-7}\right) \cdot 10^{-v\left(9,5-K_{0}\right)}}{S \cdot T}
$$

where $\mathrm{S}$ is the surface area of the selected area $\left([\mathrm{S}]=\mathrm{km}^{2}\right), \mathrm{T}-$ duration $([\mathrm{T}]=$ years $)$.

Analysis of variations is possible only with a sufficiently large number of earthquakes. at $v=0.4$ and $\mathrm{N}=150$, the standard deviation $S_{\gamma}$ is 0.04 , that is, $9 \%$.

Seismic activity A10 is calculated from the number of earthquakes $\mathrm{N}$ and the slope of the recurrence graph and is reduced to an area of $103 \mathrm{~km}^{2}$ (for the near zone of reservoirs in terms of the area of influence) and a time interval of one year. 
Around the Gissarak, Pachkamar, and Tupalang reservoirs of South Uzbekistan, a network of 7 local and 3 regional seismic stations have been set up to provide the possibility of registering earthquakes with energy classes $\mathrm{K} \geq 7$.

\section{Results and Discussion}

The Gissarak reservoir (Kashkadarya region) is located in the middle course of the Aksu River, which originates in the mountains on the northern slopes of the Gissar mountain systems.

The valley of the river, where the reservoir is located, is characterised by steep sides, large slopes of channels, relatively little preservation of terrace surfaces, and a weak distribution of young Quaternary deposits [22].

Historically, it is known that strong and destructive earthquakes occurred within a radius of up to $100 \mathrm{~km}$ in the area of the Gissarak reservoir, such as the Karatagskoe earthquake of 1907 with a magnitude of 9-10 on the MSK scale (magnitude $\mathrm{M}=7.3$; the epicenter is $70 \mathrm{~km})$, Baysun, 1935, with a magnitude of 8- 9 points (40-60 km south of the reservoir, with $\mathrm{M}=6.2$ ) and the Chuyanchinskoye 1911 with a force of 8 points (90-100 $\mathrm{km}$ east of the reservoir, with $\mathrm{M}=6.1$ ).

Seismic studies carried out earlier in the period 1973-1981 and in subsequent years showed that the territory of southern Uzbekistan is characterised by high seismicity, where earthquakes of magnitude $8(\mathrm{M} \geq 7)$ can occur $[11,22]$.

The base of the dam of the Gissarak reservoir is located in a single tectonic block in a seismicity zone of 8 points [21]. Therefore, the placement of seismic receivers in this area is designed in such a way as to provide a three-dimensional environment of the volume of rocks of interest in terms of assessing stability $[4,19]$.

The distance between the receivers of seismic waves is about 100-500 meters, while the observations cover the volume of rocks with a maximum transverse dimension of 400-1100 $\mathrm{m}$.

There were eight measuring points in the reservoir area. The seismic station at the base of the dam was in continuous recording mode. With the help of 24 receivers, a database of digital records was compiled.

The main station was located in an adit $0.5 \mathrm{~km}$ from the dam. Separate records during the growing season were made on the left side of the reservoir bowl and the dam. Also, two measuring points worked in the localisation mode of local fluctuations.

More than 450 records were made, of which 34 were related to high-frequency vibrations from earthquakes. The synchronous recording was carried out on the dam's crest and in the zone of the beginning of water entry into the reservoir (12 km from the dam site).

Variation of non-stationary two measuring points with translation according to the established time scale and the profiles of the starboard side of the bowl was carried out with the participation in the processing of the above-mentioned stationary stations. Varying the measuring points of observation (points - starboard), analog stations worked in the presence of one horizontal component of the record.

There weren't enough of them. Therefore, the method of the non-stationary shift of measuring points was used [24]. The highest density of seismic events is observed in the southeastern part of the reservoir (southern Tien Shan). They are also partly found in the North Afghan geodynamic test site (Northern Pamir).

The lowest density is in the western part of the territory. Table 1 below shows the station detection thresholds compared to others, including the opening date of stations at various observation points. 
Table 1. Comparison of useful signal detection thresholds for engineering seismometric channels (for Gindikush and local earthquakes with $\mathrm{M}=3.2-4.5$ according to the IRIS Energy Catalog)

\begin{tabular}{|c|c|c|c|c|c|c|c|c|}
\hline \multirow{2}{*}{$\begin{array}{c}\text { Observa } \\
\text { tion } \\
\text { point }\end{array}$} & \multirow[b]{2}{*}{ The code } & \multirow{2}{*}{$\begin{array}{c}\text { Station } \\
\text { opening } \\
\text { date }\end{array}$} & \multicolumn{6}{|c|}{ Detection thresholds } \\
\hline & & & $\begin{array}{l}\mathrm{N}-\mathrm{S} \\
\mathrm{mB}\end{array}$ & $\begin{array}{l}\mathrm{N}-\mathrm{S} \\
\mathrm{mB}\end{array}$ & $\begin{array}{c}\text { E-W } \\
\mathrm{mB}\end{array}$ & $\begin{array}{c}\text { E-W } \\
\mathrm{mB}\end{array}$ & $\begin{array}{c}\mathrm{Z} \\
\mathrm{mB}\end{array}$ & $\begin{array}{c}\mathrm{Z} \\
\mathrm{mB}\end{array}$ \\
\hline Gissarak & GSR & $\begin{array}{c}26.10 .201 \\
4\end{array}$ & 4.0 & 3.9 & 1.3 & 1.4 & 0.5 & 0.4 \\
\hline $\begin{array}{c}\text { Pachka } \\
\text { mar }\end{array}$ & PCHK & $\begin{array}{c}06.03 .201 \\
5\end{array}$ & 3.8 & 3.7 & 4.0 & 3.9 & 0.3 & 0.3 \\
\hline
\end{tabular}

For each seismometric channel of the station, detection thresholds are also shown in $\mathrm{mV}$ (millivolts), exceeding any of them under the action of seismic vibrations transferred the station from the standby mode to the "earthquake recording" mode.

Over the entire observation period, the seismic workstations CPC KM/V-F from/s "Shabat" with the group of seismic stations "Gissarak" and "Pachkamar" continued to stably record seismic events. The group of s / s "Tupalang" located in the near the Tupalang reservoir is also included in the processing.

All these stations jointly provided the ability to register earthquakes with $\mathrm{K} \leq 7$ energy class occurring in southwestern Uzbekistan.

To study seismicity, the parameters of seismic sources were preliminarily determined: time in the source, coordinates of epicenters, depths of hypocenters and magnitudes, and replenishment of the local catalog of earthquakes in the near zones of the Gissarak reservoir.

Based on the distribution of earthquakes, an assessment of their parameters (seismic activity, maximum earthquake magnitude), it is possible to identify potential seismic zones by contours and assess the level of seismic risk.

The monitoring of seismicity parameters of local areas and near zones of the Gissarak reservoir includes an assessment of the level of regional seismicity according to the current scale; construction of schemes of areal distribution of local and regional earthquakes; A10 activity; the slope of the earthquake recurrence graph.

The local catalog was compiled for energy classes $K \leq 7$ (magnitude $M \geq 2$ ) and included more than 500 earthquakes that occurred from 2008 to mid-2016 within a radius of up to $100 \mathrm{~km}$ from the dam site [1].

When studying the seismicity of the Gissarak reservoir zone, weak local earthquakes with $\mathrm{K}=7$ were separated. The manifestation of the above shaking has increased since 2008 on records of seismic stations operating in standby mode and since 2010 on digital records.

Weak seismic shocks intensified in 2011 and 2013 and by the middle of 2013 and 2014 when the water level in the reservoir rose above the $\mathrm{H}=80 \mathrm{~m}$ marks [11].

From the end of 2014 to August 2015, more than 30 seismic events were recorded. As for the slope of the repeatability graph $\gamma$, the discrepancy lies within the error limits. For the average long-term value of the slope of the recurrence graph for the Gissarak region, $\gamma=$ $0.57 \pm 0.07$ should be left.

For the last two time intervals, the value of $\gamma$ of the repeatability graph has sharply decreased. During this period, the filling of the reservoir began, and in the shortest time after that, the frequency of changes in the volume of water increased, which probably led to a change in $\gamma$ (Table 2). 
Table 2. Value of the parameters of the recurrence graph of the Gissarak region

\begin{tabular}{|c|c|c|c|c|}
\hline № & $\begin{array}{c}\text { Observation } \\
\text { periods }\end{array}$ & Class K & $\begin{array}{c}\text { The value of } \\
\gamma\end{array}$ & Note \\
\hline 1 & $1985-1987$ & $8 \div 12$ & $0.42 \pm 0.06$ & $\begin{array}{c}\text { The period of the beginning of } \\
\text { filling the reservoir. }\end{array}$ \\
\hline 2 & $1987-2014$ & $8 \div 12$ & $0.44 \pm 0.07$ & $\begin{array}{c}\text { The period of the regime } \\
\text { operation of the reservoir. }\end{array}$ \\
\hline 3 & $2014-2016$. & $7 \div 12$ & $0.57 \pm 0.03$ & Study period \\
\hline
\end{tabular}

Comparison of the values of the parameters of the recurrence graph for individual intervals in the periods 1966-1973 (before construction in the area of the reservoir), 19731983. (during the period of construction and the beginning of filling the reservoir) and 1987-2010 (during operation) shows that the latter is characterised by a decrease in the parameter from $\gamma=0.57$ to $\gamma=0.34$.

Calculations were carried out using formulas (1), (2), and (3). The values of the $\gamma$ parameter obtained for different periods of averaging show that the seismic regime during the period, including the first cycle - the beginning of reservoir construction (1972-1983), differs from the second cycle - the beginning of filling the reservoir (1985-1987) and differs from the third cycle - operation of the reservoir (1987-2016).

The Packham dam of the Arsk reservoir is located on the Guzar River in an area with high seismicity - 8 points. The distance between the Gissarak and Pachkamar reservoirs is about $70 \mathrm{~km}$ (southwest of Gissarak). Both structures are classified as structures of the first strength class $[7,9]$.

Engineering seismometric observations at the facilities were organised at the end of 1986-87. (according to I.Kh. Timber and N.M. Dzhuraev [9]) and at the beginning of construction.

Since 1990, engineering seismometric observations have been improved and switched to a permanent registration scheme. The same situation was in the area of the Tupalang reservoir, with a difference of only three years before the start of the operation.

From 1990 to 2006, a new station in the area of the Pachamar reservoir was included in the observation system. Full synchronous operation of engineering seismometric observations at the facilities was organised at the end of 1986-1987 (according to I.Kh. Timbekov and N.M. Dzhuraev [9]) and at the beginning of construction.

Since 1990, engineering seismometric observations have been improved and switched to a permanent registration scheme. The same situation was in the area of the Tupalang reservoir, with a difference of only three years before the start of the operation.

From 1990 to 2006, a new station in the area of the Pachamar reservoir was included in the observation system. Full synchronous operation of all stations has been ensured since 2014.

Therefore, Table 3 shows the time intervals by dividing annual cycles according to the maximum possible representativeness. They also turned out to be more refined and generalised than in $[1,12,24]$.

Another digitals / s "Pancamer Dam" has been installed in the area of the Pachkamar reservoir in the area of the dam crest. During the observation period in the Gissarak, Pachkamar, and Tupalang reservoirs, more than 1300 synchronous records of earthquakes at all stations were selected, systematised, and processed from the recorded earthquakes.

All stations have been provided since 2014 .

Therefore, Table 3 shows the time intervals by dividing annual cycles according to the maximum possible representativeness. They also became more refined and generalised than in $[1,12,23]$. 
Another digitals/s "Pancamer Dam" has been installed in the area of the Pachkamar reservoir in the area of the dam crest. During the observation period in the Gissarak, Pachkamar, and Tupalang reservoirs, more than 1300 synchronous records of earthquakes at all stations were selected, systematised, and processed from the recorded earthquakes.

Operational regime from 2010 to mid-2016 and the time of an earthquake with different energy classes in the near zone of the reservoir (Fig. 1 showed that each peak of the water pressure column corresponds to an earthquake of a certain energy class.

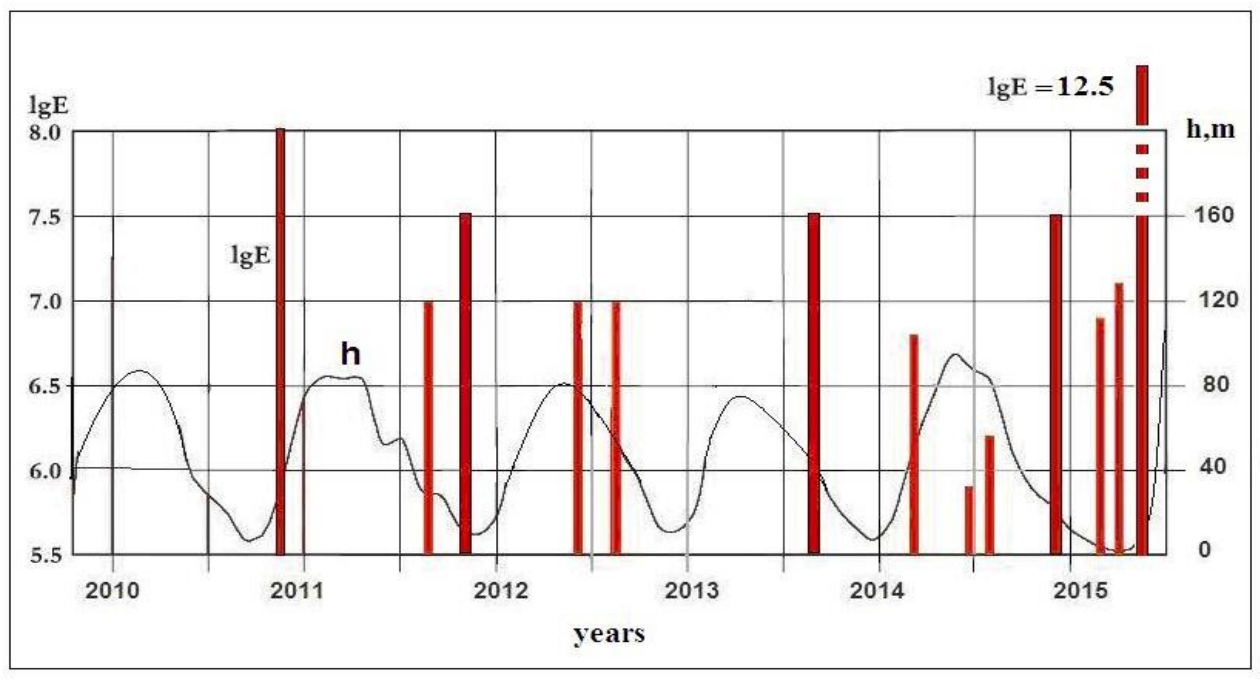

Fig. 1. Average operating regime of the Gissarak reservoir (change in water height $\mathrm{h}$ in meters) and the time of an earthquake with different energy classes $(K=\lg E)$ in the near zone of the reservoir from 2010 to mid-2016 [23].

By analysing the possibility of triggered shear along the tectonic faults that are highlighted in the Gissarak Reservoir Scheme, an analytical relationship with loaddischarge variation is determined.

At the end of 2015 and in the first months of 2016, there was a sharp increase in the intense water volume drop in the Gissarak reservoir. A tectonic earthquake with magnitude $\mathrm{M}=4.9$ and energy class $\mathrm{K}=12.5$ occurred at a depth of $10 \mathrm{~km}$ on 15 April $2016,12 \mathrm{~km}$ west of its centre and $14 \mathrm{~km}$ east of the town of Kitab (coordinates $=67.24$; $=39.06$ ). The intensity of the shaking at the epicentre was I=6-7 magnitude (MSK). In December 2015, the Gissarak site reported the possibility of an earthquake with an energy class higher than $\mathrm{K} \geq 11$ in the near zone of the reservoir. We classified this earthquake as induced [22,24]. This assumption is in satisfactory agreement with the results obtained in the works of D.V. Ramana and etc. [13], J.M. Ferreira and etc. 17], G.Kaufmann, F.Amelung [18], A.Kangi, N.Heidari [20], H.Ping, H.Yuliang [25] in Koina and Varna reservoirs (India), Asu (Brazil), Mid (USA), Karun III (Iran) and in zones of big water reservoirs of China under completely different seismotectonic conditions.

\section{Conclusions}

Analysis of the total and background seismicity of the Hissarak, Pachkam Ar and Tupalang reservoir zones in Southern Uzbekistan has shown that the distribution of local earthquake focuses in the study area is different for different years. According to materials from 2007 to 2014 with energy class $\mathrm{K} \geq 8.0$ and in recent years from 2014 to June 2016 with $\mathrm{K} \geq 7.0$, 
there is a strong variation in the number of earthquakes and densification of epicenters in narrow zones that coincide with the strike direction of local fault structures in the seismic regime.

A unique catalogue of local earthquakes in their influence zone has been compiled by tracking the seismicity levels of the Gissarak, Pachkam Ar and Tupalang reservoirs in southern Uzbekistan. An important feature of the created catalogue of local earthquakes is its comparability both with regional catalogues and transboundary states' catalogues.

Tracking of local seismicity levels of reservoir zones in South Uzbekistan has revealed several evidence of the negative impact of large hydro-technical reservoirs on deformation and seismic state of zones of the active impact of reservoirs.

\section{Acknowledgements}

The authors would like to thank the Academy of Sciences and the Ministry of Innovative Development of the Republic of Uzbekistan for financial and organisational support in carrying out research under the State Programs of Basic and Applied Research for 2017-2020 Contracts FA-F-8008 and PP-2017091115.

\section{References}

1. Khamidov L.A., Artikov F.R., Khamidov H.L. Possibilities of organising tracking of local seismicity in the near zones of reservoirs in Uzbekistan, Deep structure, geodynamics, thermal field of the Earth, interpretation of geophysical fields - Ninth scientific readings by Yu.P. Bulashevich. - 18 to 22 September, pp. 132-139, (2017)

2. Telsca L., Analysis of the cross-correlation between seismicity and water level in Koyna area (India), Bull. Seismol. Soc. Am. 100, pp. 2317-2321., (2010) http://dx.doi.org/10.1785/0120090392.

3. H.K. Gupta, A Review of Recent Studies of Triggered Earthquakes by Artificial Water Reservoirs with Special Emphasis on Earthquakes in Koyna / India. EarthScience Reviews 58 (3-4) pp. 279-310. (2002). http://dx.doi.org/10.1016/S0012$\underline{\text { 8252(02)00063-6 }}$

4. Singh C., Bhattacharya, P.M. and Chadha, R.K. Seismicity in the Koyna-Warna Reservoir Site in Western India: Fractal and b-Value Mapping. Bulletin of the Seismological Society of America, 98, pp. 476-482, (2008) http://dx.doi.org/10.1785/0120070165

5. Carder D.S., Seismic investigations in the Boulder Dam area, 1940-1944, and the influence of reservoir loading on earthquake activity, Bull. Seismol. Soc. Am. 35 pp. 175-192, (1945) https://www.seismosoc.org/publications/bssa/

6. Dams and development. The Report of the World Commission on Dams. EARTHSCAN. p. 404, November (2000), http://digitalcommons.wcl.american.edu

7. Kasymov S.M., Dzhuraev N.M, Timbekov I.Kh, V.M. Mirzaev, Seismic microzoning of construction areas for hydraulic structures in Uzbekistan. Tashkent, Fan, p. 155, (1974)

8. Plotnikova L.M., Matasov L.M., Surov V.P. and Makhmudova V.I., Features of the manifestation of earthquakes in the area of the Charvak reservoir during the period of maximum filling. Seismological research in Uzbekistan, pp. 46-53, Tashkent, (1979)

9. I.Kh. Timbekov, N.M. Dzhuraev, M.A. Tuychieva On the achievements of complex engineering and seismological studies carried out in the area of the forthcoming construction of hydraulic structures in seismically active zones of Uzbekistan. Problems of seismology in Uzbekistan, 3 pp. 54-63, Tashkent, (2006) 
10. Khamidov L.A., Local Seismicity of Reservoir Areas Based on Digital Seismometric Observations. Problems of Cybernetics and Informatics. International Conference, III. Baku. pp. 85-89, Azerbaijan, (2012), DOI: 10.1109 / ICPCI.2012.6486349

11. Kh.L.Khamidov, FIIbragimov Changes in seismicity parameters in the zone of influence of large reservoirs of southern Uzbekistan, XII International Youth Conference "Modern Techniques and Technologies in Scientific Research", 22-24 April, pp. 311-317, Bishkek, Kyrgyzstan, (2020)

12. L.A.Khamidov, I.M.Alimukhamedov, F.R.Artikov, H.L.Khamidov. Parameters for assessing the local geodynamics of the near zones of reservoirs. The Fifth Tectonophysical Conference at the IPE RAS. "Tectonophysics and topical issues of earth sciences" Materials of reports of the All-Russian conference with international participation, October 5-9, 2020, pp. 571-578, Moscow, (2020),

13. Ramana, D.V., Pavan Kumar, J., Singh, R.N. and Chadha, R.K. Co-Integration Models for Koyna and Warna Reservoirs, India. International Journal of Geosciences, 6, pp. 1173-1178, (2015)

14. J.M. Ferreira, R.T. De Oliveira, M. Assumpção, J.A.M. Moreira, R.G. Pearce, M.K. Takeya, Correlation of seismicity and water level in the Açu reservoir - an example from Northeast Brazil. Bulletin of the Seismological Society of America 85 (5) pp. 1483-1489, (1995)

15. Ferreira J.M., França G.S., Vilar C.S., do A.F. Nascimento, F.H.R. Bezerra, M. Assumpção, Induced seismicity in the Castanhão reservoir, NE Brazil - preliminary results. Tectonophysics 456 (1-2), pp. 103-110, (2008)

16. Kaufmann G., Amelung F., Reservoir-induced deformation and continental theology in the vicinity of Lake Mead, Nevada. Journal of Geophysical Research: Solid Earth 105 (B7). pp. 16341-16358, (2000)

17. Levi K.G., Kozyreva E.A., Zadonina N.V., Chechelnitsky V.V., Gilyova N.A. Problems of induced seismicity and engineering geological protection of reservoirs of the Baikalangara cascade // Geodynamics \& Tectonophysics. 4 (1), pp. 13-36, Russia, (2013), https://doi.org/10.5800/GT-2013-4-1-0089

18. Kangi A., Heidari N., Reservoirinduced seismicity in Karun III dam (Southwestern Iran). Journal of Seismology 12 (4) pp. 519-527, (2008), https://doi.org/10.1007/s1095000891044

19 Artikov T.U., Ibragimov R.S., Ibragimova T.L. Mirzaev M.A Complex of general seismic zoning maps OSR-2017 of Uzbekistan Geodesy and Geodynamics, 11(4), pp. 273-292, (2020), https://doi.org/10.1016/j.geog.2020.03.004

20. Khamidov LA, Ziyaudinov FF, Artikov FR, Fakhriddinov Zh.F. Results of engineering seismometric observations in the area of the Gissarak reservoir. Geology and mineral resources, № 5, pp. 58-65, (2016)

21. Alimukhamedov I.M., Shukurov Z.F., Khamidov H.L., Ziyomov B.Z., Fakhriddinov J.F. Indicators of local geodynamic activity of the earth's crust in reservoir zones. Geology and mineral resources, 3, pp. 37-42, Tashkent, (2014)

22. Khamidov H.L., Artikov F.R., Local seismic events under the action of reservoir loading. Modern technology and technology in scientific research. International Youth Conference, pp. 271-273, Bishkek, (2016)

23. H. Ping, H. Yuliang, Advances in reservoirinduced seismicity research in China. Tectonophysics 209 (1-4) pp. 331-337, (1992) 